\title{
Potential poultry and meat products contamination by aflatoxin B1 due to fungal presence in Portuguese poultry units
}

\author{
S. Viegas ${ }^{1,2}$, J. Malta-Vacas ${ }^{1}$, R. Sabino ${ }^{3}$, \\ C. Veríssimo ${ }^{3} \&$ C. Viegas ${ }^{1}$ \\ ${ }^{1}$ Higher School of Health Technology of Lisbon, \\ Institute Polytechnic of Lisbon, Portugal \\ ${ }^{2}$ CIESP, Centro de Investigação e Estudos em Saúde Pública, \\ Escola Nacional de Saúde Pública, ENSP, \\ Universidade Nova de Lisboa, Portugal \\ ${ }^{3}$ National Institute of Health Dr. Ricardo Jorge, \\ Mycology Laboratory, Portugal
}

\begin{abstract}
The impact of mycotoxins on human and animal health is well recognized. Aflatoxin $\mathrm{B}_{1}\left(\mathrm{AFB}_{1}\right)$ is by far the most prevalent and the most potent natural carcinogen and is usually the major aflatoxin produced by toxigenic fungal strains. Data available, points to an increasing frequency of poultry feed contamination by aflatoxins. Since aflatoxin residues may accumulate in body tissues, this represents a high risk to human health. Samples from commercial poultry birds have already presented detectable levels of aflatoxin in liver. A descriptive study was developed in order to assess fungal contamination by species from Aspergillus flavus complex in seven Portuguese poultry units. Air fungal contamination was studied by conventional and molecular methods. Air, litter and surfaces samples were collected. To apply molecular methods, air samples of 300L were collected using the Coriolis $\mu$ air sampler (Bertin Technologies), at $300 \mathrm{~L} / \mathrm{min}$ airflow rate. For conventional methodologies, all the collected samples were incubated at $27^{\circ} \mathrm{C}$ for five to seven days. Through conventional methods, Aspergillus flavus was the third fungal species (7\%) most frequently found in 27 indoor air samples analysed and the most commonly isolated species (75\%) in air samples containing only the Aspergillus genus.
\end{abstract}


Moreover, A. flavus presented the highest level of airborne spores $\left(>2000 \mathrm{CFU} / \mathrm{m}^{3}\right)$. Using Real-Time PCR, aflatoxigenic strains of $A$. flavus complex were obtained in three indoor samples from two different poultry units. Concerning new litter $A$. flavus was isolated in $9.9 \%$ of the samples and was not found in the used litter. Regarding surfaces A. flavus was found in $24 \%$ of the samples. It seems relevant to suggest that regular survey of aflatoxins should be done to evaluate food chain contamination aiming to create data to permit a detailed health risk assessment to poultry meat consumers.

Key words: poultry, aflatoxins, aflatoxin B1, meat contamination.

\section{Introduction}

In recent decades, the question of mould toxicity has attracted attention, especially in the fields of agriculture and food industry. Microscopic filamentous fungi often contaminate vegetal and animal products, and are commonly a source of diseases in man and animals [1]. The reason for an increasing interest in this field is their ability to produce secondary metabolites - mycotoxins - that can cause adverse effects, such as carcinogenesis and mutagenicity [2]. The presence of mycotoxins in food and feed stuff is result of a complex series of interaction among the causative fungi, the contaminated products, the various environmental factors and the intoxicated host [2].

Conditions that favor contamination by mycotoxins include excessive moisture both in field and post harvest storage, high humidity, extreme temperature, drought stress, and insect damage to crops [3].

Humans are exposed directly to mycotoxins through consumption of contaminated foods. Handling contaminated feed can also result in exposure to mycotoxins through the skin and by inhalation [4].

The impact of mycotoxins on human and animal health is well recognized. However, establishing a causal relationship between mycotoxins exposure and human disease can be difficult [5].

Aflatoxins, toxic metabolites mainly produced by Aspergillus flavus and Aspergillus parasiticus, are naturally occurring contaminants of food. Although aflatoxins have been a problem throughout history, they have been recognized as significant contaminants within agriculture only since the 1960s. Aspergillus growth is influenced mainly by temperature, moisture content and storage time. As aflatoxins often accumulate during food storage, post-harvest control at the farms aims to minimize fungal growth and, subsequently, aflatoxin production [6].

The four major types of the aflatoxins are called $B_{1}, B_{2}, G_{1}$, and $G_{2}$ based on their fluorescence under UV light (blue or green, respectively). Aflatoxin $B_{1}$ $\left(\mathrm{AFB}_{1}\right)$ is by far the most prevalent and the most potent natural carcinogen and is usually the major aflatoxin produced by toxigenic strains [7-9].

Indirect exposure of humans to aflatoxins occurs through foods (primarily milk, liver, and eggs) derived from animals that consume contaminated feeds [10]. Aflatoxins are deleterious to poultry and their contamination in feed is practically unavoidable $[11,12]$. 
Crops contaminated with aflatoxins are a worldwide problem and approximately $25 \%$ of world's food supply is contaminated with mycotoxins annually $[13,14]$. Conditions that favor contamination by mycotoxins include excessive moisture both in field and post harvest storage, high humidity, temperature extremes, drought stress, and insect damage to crops [3].

Adverse weather conditions pre-harvest in many parts of the world arising from global climate change can conduct to an increasing frequency of mycotoxin contamination of poultry feeds. The complex nature of modern poultry rations including the increasing use of potentially contaminated by-products such distillers' dried grains adds the possibility of toxicological synergy between combinations of mycotoxins thereby increasing the severity of the response of poultry to contaminated feeds [15].

Acute or chronic aflatoxicosis in poultry birds results in decreased meat and egg production, immunosuppressant, and hepatotoxicosis [16-18]. Aflatoxin residues may also appear in body tissues and samples collected from the commercial poultry birds presented detectable levels of aflatoxin in liver [19-21].

As in human species, the liver is the most severely affected organ in poultry, primary consequences being hepatotoxicity and carcinogenicity [11, 22].

As far as public health problems are concerned, food contamination by aflatoxins poses a high risk to human health including acute aflatoxicosis, hepatocellular carcinoma, hepatitis B virus infection and growth impairment [23].

In humans, $\mathrm{AFB}_{1}$ is activated by cytochromes $\mathrm{P} 450$ to $\mathrm{AFB}_{1}-8$, 9-exoepoxide and $\mathrm{AFB}_{1}-8$, 9-endo-epoxide, but it is the exo-epoxide which binds to DNA to form the predominant 8,9-dihydro-8- (N7-guanyl)-9-hydroxy-AFB (AFB $_{1}-\mathrm{N} 7$ Gua) adduct [24]). $\mathrm{AFB}_{1}-\mathrm{N} 7-\mathrm{Gua}$ confers the mutagenic properties of the compound [25, 26]). Other metabolites are formed from $\mathrm{AFB}_{1}$, including AFQ1, AFM1 and AFP1. These metabolites and other naturally occurring aflatoxins (G1, B2 and G2) are poorer substrates for epoxidation and, consequently, are less mutagenic, carcinogenic and toxic than $\mathrm{AFB}_{1}$ [27].

Besides being an important public health issue, aflatoxins result in economic losses to poultry industry due to reductions in growth rate, hatchability, feed efficiency and immunity towards diseases [3, 11, 28].

Keeping in mind the concerns above mentioned a descriptive study was developed in order to assess fungal contamination by species from Aspergillus flavus complex in seven Portuguese poultry units.

\section{Materials and methods}

This study was carried out in seven poultry farms located in the district of Lisbon, Portugal, between January and May 2011. All the units have more than one pavilion where birds are kept. The pavilions have natural and mechanical ventilation, but the latter is generally only activated in summer, when temperatures rise. 
Air fungal contamination was studied by conventional and molecular methods. Twenty-seven air samples from seven poultries were collected at 140 L/minute, at one meter height, onto malt extract agar supplemented with chloramphenicol (MEA) for conventional methods. In order to apply molecular methods, air samples (300L) were collected using the Coriolis $\mu$ air sampler (Bertin Technologies), at $300 \mathrm{~L} / \mathrm{min}$ airflow rate. Each air sample was collected into a conic sterile tube containing $10 \mathrm{ml}$ sterile phosphate buffered saline and $0.05 \%$ Triton $\mathrm{X}-100$. Five $\mathrm{ml}$ from the collection liquid was centrifuged at $2500 \mathrm{~g}$ for $10 \mathrm{~min}$ and supernatant was removed to leave a $250 \mu \mathrm{l}$ pellet that was subsequently used for DNA extraction. DNA was then extracted using the ZR Fungal/Bacterial DNA MiniPrep Kit (Zymo Research) according to the manufacturer's recommendations. Confirmation of fungal DNA extraction was obtained by amplifying a fragment of the 18SrDNA gene with universal fungal primers [29]. Aflatoxigenic fungi identification was achieved by using nor-1 gene specific primers and TaqMan probes in a Real Time PCR using an iQ Real Time PCR Detection System (Bio-Rad). Reactions included 1X iQ Supermix (Bio-Rad), $0.5 \mu \mathrm{M}$ of each primer and $0.375 \mu \mathrm{M}$ of TaqMan probe in a total volume of $20 \mu \mathrm{l}$. Amplification followed a three step PCR (polymerase chain reaction): 40 cycles with denaturation at $95^{\circ} \mathrm{C}$ for $30 \mathrm{sec}$, annealing at $52^{\circ} \mathrm{C}$ for $30 \mathrm{sec}$ and extension at $72^{\circ} \mathrm{C}$ for 30 sec.

Litter samples were collected and washed in $100 \mathrm{~mL}$ of sterilized distilled water, for $30 \mathrm{~min}$ at $100 \mathrm{rpm}$ and $0.2 \mathrm{~mL}$ of this suspension was spread onto three malt extract agar plates (2\%) with chloramphenicol $(0.05 \mathrm{~g} / \mathrm{L})$. Surface samples of indoor spaces were collected by swabbing the surfaces using a 10 by $10 \mathrm{~cm}$ square stencil and then platted onto MEA. All the collected samples were incubated at $27^{\circ} \mathrm{C}$ for five to seven days. After laboratory processing and incubation of the collected samples, quantitative $\left(\mathrm{CFU} / \mathrm{m}^{3}\right.$, CFU/g and CFU $/ \mathrm{cm}^{2}$ ) and qualitative results were obtained, with identification of the isolated fungal species belonging to Aspergillus flavus complex.

\section{Results}

Through conventional methods, Aspergillus flavus was the third fungal species (7\%) most frequently found in indoor air samples analysed. It was also the most commonly isolated species (75\%) in air samples containing only the Aspergillus genus. Using Real-Time PCR, aflatoxigenic strains of A. flavus complex were obtained in three indoor samples from two different farms (Table 1). Moreover, A. flavus presented the highest level of airborne spores $\left(>2000 \mathrm{CFU} / \mathrm{m}^{3}\right)$. Aflatoxigenic strains were not identified (by Real-Time PCR) in all samples where A. flavus-complex colonies were identified by conventional methods. On the other hand, we were able to detect the presence of aflatoxigenic strains in pavilions in which strains from A. flavus-complex did not grow in culture.

Concerning the new litter analysed, isolates from $A$. flavus complex was isolated in $9.9 \%$ of the samples but they were not found in the new litter. Regarding surfaces, isolates from A. flavus complex were found in $24 \%$ of the samples (Figure 1). 
Table 1: $\quad$ Distribution of aflatoxigenic strains of $A$. flavus complex.

\begin{tabular}{|l|l|l|l|l|l|}
\hline \multirow{2}{*}{$\begin{array}{c}\text { Poultry } \\
\text { farms }\end{array}$} & \multicolumn{2}{|c|}{ Air } & Used litter & New litter & Surfaces \\
\cline { 2 - 6 } & Conventional & Molecular & Conventional & Conventional & Conventional \\
\hline 1 & + & + & + & - & + \\
\hline 2 & - & + & - & - & - \\
\hline 3 & - & - & - & - & - \\
\hline 4 & - & NA & - & - & + \\
\hline 5 & - & - & - & - & - \\
\hline 6 & + & - & - & - & - \\
\hline 7 & - & NA & - & - & + \\
\hline
\end{tabular}

Note. For molecular biology, only air samples were tested. NA, not applicable.

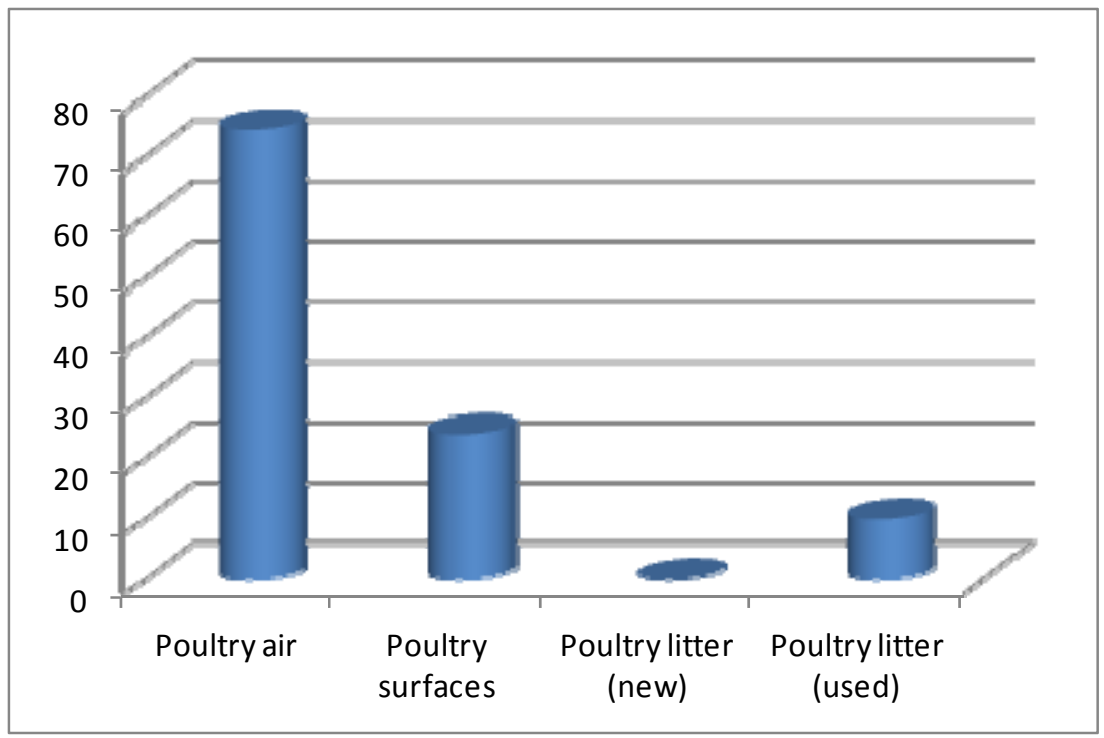

Figure 1: $\quad$ Aspergillus flavus complex distribution among Aspergillus genus.

\section{Discussion}

Fungi are often used as indicators for mycotoxins presence in agricultural settings. However, in addition to quantification, fungi need to be identified at the species level in order to relate the identified species to a certain mycotoxin, and in case of aflatoxin production, at strain level because only some strains produce this mycotoxin while other strains are non-aflatoxigenic [30, 31].

Considering the results obtained for fungal contamination is possible to conclude that there is a high contamination by fungi responsible by aflatoxin production. Moreover, data obtained in this study allowed the discrimination of aflatoxigenic strains belonging to A. flavus- complex by the use of a specific and sensitive real time PCR to detect fungi with aflatoxin-producing potential. This methodology included the use of specific primers and probes for nor- 1 gene, 
which encodes a reductase enzyme (norsolorinic acid redutase) from the aflatoxin biosynthetic pathway. Using this approach, mycotoxin-producing strains were identified irrespective of fungal morphology and cultivability. Furthermore, PCR has the advantage of specific identification of fungal DNA, including all DNA-containing fungal structures, such as hyphae, which are important contributors to mycotoxin production and bioaerosol exposure [31]. The results showed the presence of fungal strains aflatoxin-producers in two out of five poultry units studied. From those, one had a "clean" outdoor environment for aflatoxigenic fungi. These results indicate that there are sources of toxigenic fungi inside the pavilions that may be either the cover materials or the animal feed [32-34]. In addition, it is important to consider that mycotoxins may be present in the environment long after death and disintegration of the producer $[31,35]$.

Meanwhile, it is important to mention that the workers of these poultry farms were enrolled in a study aiming to assess occupational exposure to $\mathrm{AFB}_{1}$. A biomarker of internal dose was used providing information regarding recent exposure to $\mathrm{AFB}_{1}$ and its intensity. Eighteen from thirty one poultry workers displayed detectable levels of $\mathrm{AFB}_{1}$, in contrast to all individuals used as controls $(n=30)$ who showed no detectable values. These findings corroborate the hypothesis that occupational exposure to $\mathrm{AFB}_{1}$ by inhalation was occurring [36]. Moreover they also corroborate the possibility of poultry birds being exposed to $\mathrm{AFB}_{1}$. Therefore, the presence of $\mathrm{AFB}_{1}$ in meat and eggs is a quite plausible scenario.

In some experimental studies, poultry birds where fed with aflatoxin contaminated rations and resulted in the presence of aflatoxin residues in their edible tissues like liver and muscles [37]. Residues of $\mathrm{AFB}_{1}$ in liver of broiler and layer birds have been reported to vary from no detection to $3.0 \mathrm{ng} / \mathrm{g}$ by feeding 250-3310 ng/g $\mathrm{AFB}_{1}$ for variable periods [19, 37-40].

The wide variations in the tissue of aflatoxin residue concentration suggested that these levels might be influenced by different factors including dietary aflatoxin levels, duration of administration, age, type of the birds, etc. However, the effect of such factors upon concentration of $\mathrm{AFB}_{1}$ residues in poultry meat (liver and muscles), and clearance of $\mathrm{AFB}_{1}$ from the body tissues after withdrawal of dietary aflatoxin, have not been adequately studied [19].

Considering possible sources of contamination of the poultry setting [32-34], the most mentioned in the literature is the feed and probably is the most responsible for bird's exposure by ingestion. Consequently, feed becomes an indoor source for fungal contamination and also their metabolites such as mycotoxins.

In 2004, the Scientific Panel on Contaminants in the Food Chain (CONTAM Panel) from European Food Safety Authority (EFSA) concluded that the current maximum levels of $\mathrm{AFB}_{1}$ in animal feed $\left(0.020 \mathrm{mg} \mathrm{AFB}_{1} / \mathrm{kg}\right.$, Directive 2002/32/EC) provided an adequate protection from adverse health effects in target animal species. Among its recommendations, and to avoid higher level of feed contamination, the Panel encouraged regular monitoring of the presence of $\mathrm{AFB}_{1}$ in imported feedstuffs in all EU member states. In the case of Southern 
Europe countries, monitoring programmes for feed materials, especially maize and products thereof should be extended to cover materials originating from those parts of Europe, where a subtropical climate and extensive agricultural practice favour fungal growth and subsequent formation of aflatoxins [41].

Regarding human food products, the European Community and many other countries have imposed 2ng/g $\mathrm{AFB}_{1}$ as maximum tolerance level [42].

In the case of birds and following ingestion, aflatoxins are rapidly metabolized into nontoxic substances in the body [43, 44] and it may not represent a significant human health risk. However, in areas with no regulatory limits on $\mathrm{AFB}_{1}$ levels of poultry feed for instance, the secondary exposure to aflatoxins through consumption of chicken liver and meat may pose a risk to consumer's health.

Following the ALARA principle ("as low as reasonably achievable") in terms of an intension to keep the exposure to carcinogenic substances at the lowest achievable level, the levels of aflatoxins and their metabolites in human foods, like poultry meat, should be kept as low as possible. In 2007, and taking into account this principle, the CONTAM Panel of EFSA concluded that exposure to aflatoxins from all sources should be as low as reasonably achievable, because aflatoxins are genotoxic and carcinogenic. The same work group stated that data available indicate that reduction of total dietary exposure to aflatoxins could be achieved by reducing the number of highly contaminated foods reaching the market through more effective enforcement and reducing exposure from food sources other than almonds, hazelnuts and pistachios.

\section{Conclusions}

It seems relevant to suggested that regular survey of aflatoxins should be done to evaluate food chain contamination aiming to create data to permit a detailed health risk assessment to poultry meat consumers. Additionally, in poultry industry all the potential indoor sources of fungal dissemination must be monitored, aiming to assess and prevent fungal and, consequently, mycotoxin contamination.

\section{References}

[1] Paterson RRM, Lima N. How will climate change affect mycotoxins in food? Food Research International, 43: pp. 1902-1914, 2010.

[2] Mižáková A, Pipová M, Turek P. The occurrence of moulds in fermented raw meat products. Czech J. Food. Sci., 20: pp. 89-94, 2002.

[3] Coulombe Jr RA. Biological action of mycotoxins. Journal of Dairy Science, 76: pp. 880-891, 1993.

[4] Schiefer HB. Mycotoxicosis of domestic animals and their diagnosis. Can. J. Physiol. Pharmacol. 68: pp. 987-990, 1990.

[5] Smith JE, Solomons G, Lewis C, Anderson S. The role of mycotoxins in human and animal nutrition and health. Nat. Toxins, 3(4): pp. 187-192, 1995. 
[6] Strosnider H, Azziz-Baumgartner E, Banziger M, Bhat R, Breiman R, et al. Workgroup Report: Public Health Strategies for Reducing Aflatoxin Exposure in Developing Countries. Environmental Health Perspectives, 114; 12, 2006.

[7] Squire NP. Ranking animal carcinogens: a proposed regulatory approach. Sci. 214: 877-880, 1981.

[8] Reddy SV, Waliyar F. Properties of Aflatoxin and It Producing Fungi. Aflatoxin. Int. Crops Res. Inst. for the Semi-Arid Tropics.2000.

[9] Abdullah Alkhalaf N, Khaled Osman A, Ahmed Salama K. Monitoring of aflatoxins and heavy metals in some poultry feeds. African Journal of Food Science Vol. 4(4):pp. 192-199, 2010.

[10] Hayes A.W. Mycotoxins: a review of biological effects and their role in human diseases. Clin. Toxicol. 17: pp. 45-60, 1980.

[11] Coulombe Jr RA, Guarisco JA, Klein PJ, Hall JO. Chemoprevention of aflatoxicosis in poultry by dietary butylated hydroxytoluene. Animal Feed Science and Technology 121: pp. 217-225, 2005.

[12] Rawal S, Kim J, Coulombe Jr R. Aflatoxin B1 in poultry: Toxicology, metabolism and prevention. Research in Veterinary Science, 89: pp. 32533, 2010.

[13] CAST. Council for Agricultural Science and Technology. Mycotoxins: Economic and Health Risks. CAST, Ames, IA. p. 116, 1989.

[14] CAST. Council of Agricultural Science and Technology. Mycotoxins: risks in plant, animal and human systems. CAST, Ames, IA. p. 139, 2003.

[15] Smith T. Nutrigeonomics: Evaluating Mycotoxin Control Strategies. In Alltech Technical Symposium, 2010.

[16] Arafa AS, Bloomer RJ, Wilson HR, Simpson CF, Harms RH. Susceptibility of various poultry species to dietary aflatoxin. Br. Poult. Sci. 22: pp. 431436, 1981

[17] Verma J, Johr, TS, Swain BK, Ameena S. Effect of graded levels of aflatoxin, ochratoxin and their combinations on the performance and immune response of broilers. Br. Poult. Sci. 45: pp. 512-518, 2004.

[18] Khan WA, Khan MZ., Khan A Hussain, I. Pathological effects of aflatoxin and their amelioration by vitamin E in White Leghorn layers. Pak. Vet. J. 30: pp. 155-162, 2010.

[19] Asim A, Khan KNM, Cheema AH, Mir FA, Afzal M. Occurrence of aflatoxins in poultry liver and associated pathological changes. Pak. Vet. J. 2, 51-54, 1990.

[20] Bintvihok A, Davitiyananda D. Aflatoxins and their metabolites residues in chicken tissues from 5 parts (10 provinces) of Thailand. Thai. J. Health Res. 16: pp. 37-50, 2002.

[21] Hussain Z, Khan MZ, Khan A, Javed L, Saleemi MK, Mahmood S, Asi MR. Residues of aflatoxin B1 in broiler meat: Effect of age and dietary aflatoxin B1 levels. Food and Chemical Toxicology 48: pp. 3304-3307, 2010. 
[22] Klein PJ, Buckner R, Kelly J, Coulombe, R. A. Biochemical basis for the extreme sensitivity of turkeys to aflatoxin B1. Toxicol. Appl. Pharmacol. 165: pp. 45-52, 2000.

[23] Wild CP, Gong YY. Mycotoxin and human diseases: a largely ignored global health issue. Carcinogenesis 31: pp. 71-82, 2010.

[24] Iyer RS, Voehler MW and Harris TM. Adenine adduct of aflatoxin B1 epoxide. J. Am. Chem. Soc., 116, 8863-8869, 1994.

[25] Gopalakrishnan S., Harris TM and Stone MP. Intercalation of aflatoxin B1 in two oligodeoxynucleotide adducts: comparative $1 \mathrm{H}$ NMR analysis of d(ATCAFBGAT). d(ATCGAT) and d(ATAFBGCAT)2. Biochemistry, 29, 10438-10448, 1990.

[26] Kobertz WR, Wang D, Wogan GN and Essigmann JM. An intercalation inhibitor altering the target selectivity of DNA damaging agents: synthesis of site-specific aflatoxin B1 adducts in a p53 mutational hotspot. Proc. Natl Acad. Sci. USA, 94, 9579-9584, 1997.

[27] Wild CP, Turner PC. The toxicology of aflatoxins as a basis for public health decisions. Mutagenesis 17; 6: pp. 471-481, 2002.

[28] Richard JL, Stubblefield RD, Lyon RL, Peden WM, Thurston .R, Rimler RB. Distribution and clearance of aflatoxins B1 and M1 in turkeys fed diets containing 50 or $150 \mathrm{ppb}$ aflatoxin from naturally contaminated corn. Avian Diseases 30: pp. 788-793, 1986.

[29] Wu Z, Wang X, Blomquist G. Evaluation of PCR primers and PCR conditions for specific detection of common airborne fungi. J Environ Monit. 4: pp. 377-382, 2002.

[30] Thrane U, Adler A, Clasen PE, Galvano F, Langseth W, Lew H, Logrieco A, Nielsen KF, Ritieni, A. Diversity in metabolite production by Fusarium langsethiae, Fusarium poae, and Fusarium sporotrichioides. Int. J. Food Microbiol. 95: pp. 257-266, 2004.

[31] Halstensen AS. Species-specific fungal DNA in airborne dust as surrogate for occupational mycotoxin exposure? Int. J. Mol. Sci. 9: pp. 2543-2558, 2008.

[32] Health and Safety Executive. Exposure to dust and bioaerossols in poultry farming. Summary of observations and data. London: Health and Safety Executive. 2008.

[33] Just N, Duchaine C, Singh B. An aerobiological perspective of dust in cagehoused and floor-housed poultry operations. J. Occup. Med. Toxicol. 4: pp. 13, 2009.

[34] Viegas C, Carolino E, Malta-Vacas J, Sabino R, Viegas S, Veríssimo C. Fungal Contamination of Poultry Litter: A Public Health Problem, Journal of Toxicology and Environmental Health, Part A: Current Issues, 75:22-23: pp. 1341-1350, 2012a.

[35] Alborch L, Bragulat MR, Castellá G, Abarca ML, Cabañes FJ. Mycobiota and mycotoxin contamination of maize flours and popcorn kernels for human consumption commercialized in Spain. Food Microbiol. doi:10.1016/j.fm.2012.04.014, 2012. 
[36] Viegas S, Veiga L, Malta-Vacas J, Sabino R, Figueredo P, Almeida A, Viegas C, Carolino E. Occupational Exposure to Aflatoxin $\left(\mathrm{AFB}_{1}\right)$ in Poultry Production, Journal of Toxicology and Environmental Health, Part A: Current Issues, 75:22-23: pp. 1330-1340, $2012 \mathrm{~b}$.

[37] Zaghini A, Martelli G, Roncada P, Simioli M, Rizzi L. Mannanoligosaccharides and Aflatoxin B1 in Feed for Laying Hens: Effects on Egg Quality, Aflatoxins B1 and M1 Residues in Eggs, and Aflatoxin B1 Levels in Liver. Poultry Science 84:pp. 825-832, 2005.

[38] Gregory JF, Manley D. High Performance Liquid Chromatographic determination of aflatoxins in animal tissues and products. J. Assoc. Off. Anal. Chem. 64:1-6, 1981.

[39] Wolzak A, Pearson AM, Coleman TH, Pestka JJ, Gray JI. Aflatoxin deposition and clearance in the eggs of laying hens. Food Chem. Toxicol. 23: pp. 1057-1061, 1985.

[40] Bintvihok A, Thiengnin S, Doi K, Kumagai S. Residues of aflatoxins in the liver, muscle and eggs of domestic fowls. J. Vet. Med. Sci. 64: pp. 10371039, 2002.

[41] Opinion of the Scientific Panel on Contaminants in the Food Chain on a request from the Commission related to Aflatoxin B1 as undesirable substance in animal feed. (Request $N^{\circ}$ EFSA-Q-2003-035). The EFSA Journal 39: pp. 1-27, 2004.

[42] Anonymous. Worldwide regulations for mycotoxins in food and feed in 2003. FAO Food and Nutrition Paper 81. Food and Agriculture Organization, U.N. Rome, pp. 48-126. 2004.

[43] Trucksess MW, Stoloff L, Young KY, Wyatt RD, Miller BL. Aflatoxicol and aflatoxins B1 and M1 in eggs and tissues of laying hens consuming aflatoxin contaminated feed. Poult. Sci. 62: pp. 2176-2182, 1983.

[44] Chen C, Pearson AM, Coleman TH, Gray JI, Pestka JJ, Aus SD. Tissue deposition and clearance of aflatoxins from broiler chickens fed a contaminated diet. Food Chem. Toxicol. 22: pp. 447-451, 1984. 